patients using immunofluorescence for the markers CX3CR1 and CD68.

Methods Formalin fixed paraffin embedded tissue blocks were obtained from an area of the lung as far distal to the tumour as possible from COPD patients, smokers (S) and healthy nonsmokers (HNS) undergoing lung resection for lung carcinoma. Sections were labelled with an anti-CX3CR1 antibody and detected using an Alexafluor conjugated secondary antibody. Immunohistochemical detection of CD68 (enzymatic non-biotin amplification technique) confirmed the macrophage phenotype of CX3CR1+ cells.

Results All CX3CR1+ cells expressed CD68. The diameters of COPD macrophages were greater than controls (Table 1). Intravascular CX3CR1+CD68 ${ }^{+}$macrophages were observed in COPD and $\mathrm{S}$ (Table 1).

\begin{tabular}{llll} 
Abstract P105 Table 1 & & & \\
\hline & $\begin{array}{l}\text { COPD } \\
(\mathrm{n}=9)\end{array}$ & $\mathrm{S}(\mathrm{n}=9)$ & HNS $(\mathrm{n}=6)$ \\
& 11.6 & 10.3 & 10 \\
\hline $25^{\text {th }}$ percentile $(\mu \mathrm{m})$ & 13.9 & $12.2^{*}$ & $12.1^{*}$ \\
Median $(\mu \mathrm{m})$ & 16.5 & 14.4 & 13.9 \\
$75^{\text {th }}$ percentile $(\mu \mathrm{m})$ & 15.6 & 22.2 & 0 \\
Vessels with intra-vascular macrophages $(\%)$ & & & \\
\hline
\end{tabular}

The Kruskal-Wallis test with application of Dunn's post-test was used to determine the statistical significance of differences observed in the alveolar macrophage diameter between the three groups. ${ }^{*} p<0.0001$ against COPD.

Conclusion Increased macrophage size in COPD may be linked to altered function. Pulmonary intravascular macrophages have been observed in other mammalian species and may promote pulmonary inflammation through direct release of cytokines into the pulmonary circulation.

\section{P106 TISSUE FACTOR PATHWAY INHIBITOR (TFPI) IS CLEAVED BY MULTIPLE PROTEASES IN COPD LUNGS TO AFFECT CIRCULATING TFPI LEVELS}

B Mallia-Milanes, H Bailey, G Meakin, A Sheehan, A Knox, C Bolton, S Johnson. University of Nottingham, Nottingham, UK

\subsection{6/thoraxjnl-2015-207770.243}

Background Tissue factor pathway inhibitor (TFPI) attenuates intravascular coagulation, a function limited by its proteolysis. Airway inflammation in COPD is associated with protease activity and intravascular thrombotic events, yet the link between proteolysis of TFPI in the airways and intravascular thrombosis in COPD is unexplored.

Aims To explore the presence and processing of TFPI in COPD airways and its relationship to plasma TFPI levels.

Methods COPD sputum and blood were collected at exacerbation and when stable. In vitro cleavage of TFPI was explored by incubation with proteases and Western blotting. TFPI presence and cleavage in sputum was detected by Western blotting. To determine the main protease/s involved in TFPI cleavage, sputum was spiked with recombinant TFPI in the presence of protease inhibitors, followed by Western blotting.

Results TFPI was cleaved in vitro by Matrix Metalloproteinase (MMP)-12, Neutrophil Elastase (NE) and urokinase-type plasminogen activator (uPA) to $<20$.

Conclusion TFPI is cleaved by NE in COPD airways, leading to lower circulating levels. Further studies are needed to determine if lower circulating TFPI levels lead to increased intravascular thrombotic events in COPD.

\section{P107 FUNCTIONAL SIGNIFICANCE OF THE NITRIC OXIDE- ASYMMETRIC DIMETHYLARGININE-DIMETHYLARGININE DIMETHYLAMINOHYDROLASE (NO-ADMA-DDAH) AXIS IN TGF- $\beta$ MEDIATED EPITHELIAL-MESENCHYMAL TRANSITION}

HK Lota, JM Leiper. Nitric Oxide Signalling Group, MRC Clinical Sciences Centre, Imperial College London, London, UK

10.1136/thoraxjnl-2015-207770.244

Background Transforming growth factor (TGF)- $\beta$ is a key mediator of epithelial-mesenchymal transition (EMT), a pathogenetic

\section{1a) iNOS Inhibition: E-cadherin Levels}

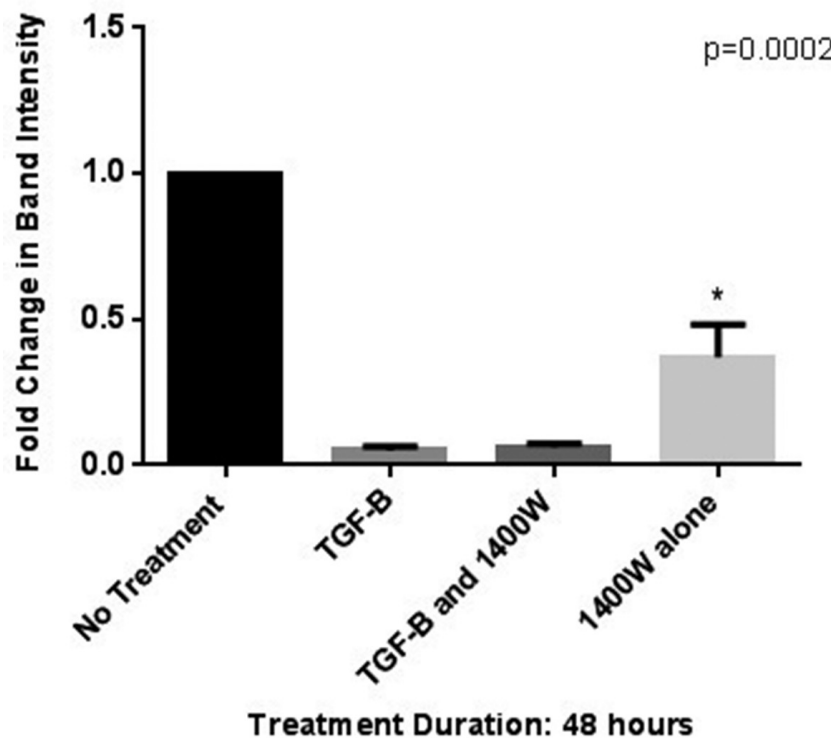

1b) Pan-NOS Inhibition: E-cadherin Levels

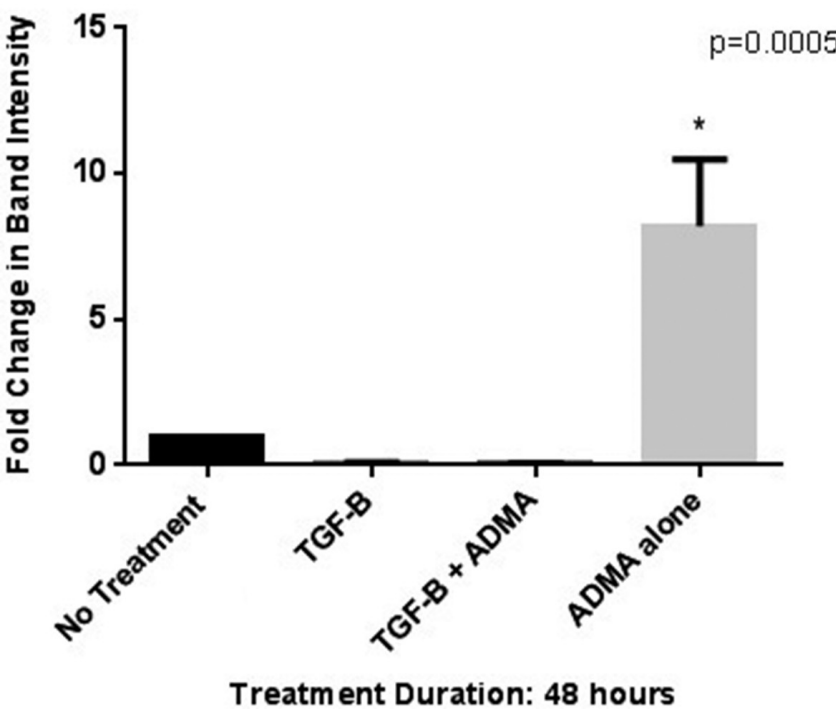

Abstract P107 Figure 1 Fold change in band intensity of E-cadherin levels corrected for tubulin on Wastern blotting: 1a) Treatment with $140 \mathrm{~W}, 1 \mathrm{~b}$ ) Treatment with ADWA ( $p$ values $=0.0002$ and 0.0005 respectively on one-way ANOVA) 